\title{
US cold snap fuels climate debate
}

Links are tenuous between Arctic warming and the extreme cold weather caused by a weak 'polar vortex'.

\section{Jeff Tollefson}

08 January 2014

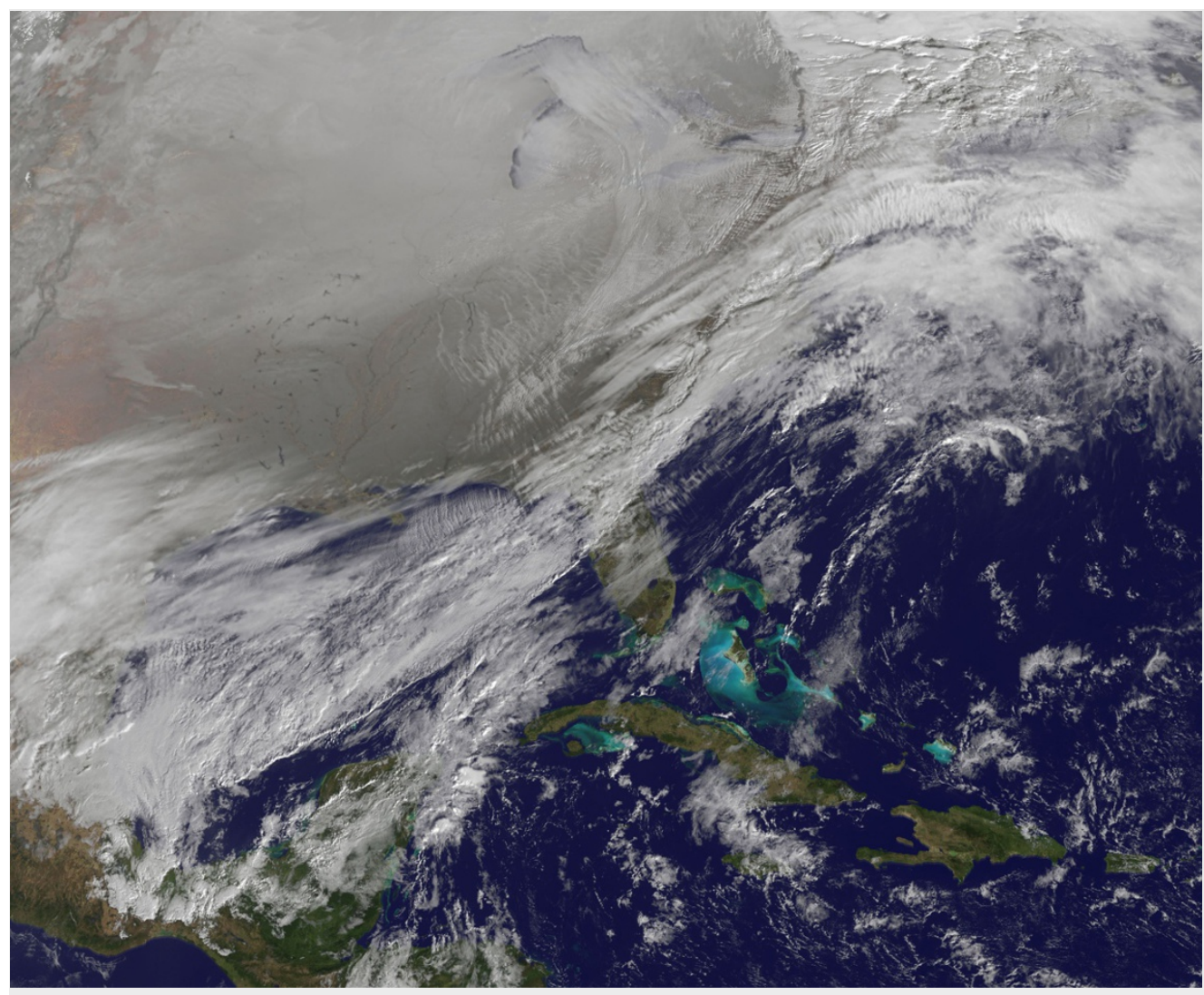

NOAAINASA GOES Project

A weakening of the jet stream allowed bitterly cold air (top left) from the Arctic to enter the United States this week.

The past several days have seen much of the United States gripped by freezing temperatures as the northerly jet stream pushed Arctic air south across North America. This has provided fuel for global-warming sceptics, even as scientists debate whether the extreme cold might in fact be a consequence of a warming climate. Nature takes a look at the underlying science.

\section{What is the 'polar vortex'?}

The polar jet stream is a natural product of Earth's rotation and climate system, created as warm air from the south merges with cold Arctic air. Most of the time it is fairly stable, circling the planet and effectively containing the cold air within the Arctic. But this orderly circulation occasionally breaks down, and a meandering jet stream can carry cold air south while allowing pockets of warm air to push farther north. Similar events have happened in the past.

The eastern United States has experienced a number of severe winters in recent years. Does this undercut globalwarming theory?

No. Extreme weather of all sorts is part of the climate system, and the effects of global warming are projected to play out over decades to centuries. If anything, some researchers think that strong Arctic warming can contribute to extreme cold snaps.

\section{How could warming in the Arctic destabilize the jet stream?}

Arctic warming is leading to declines in sea ice and increased snowmelt on land. Because ice and snow are bright, they reflect sunlight 
back into space. When they melt, more solar energy can be absorbed by the Arctic. One theory is that a warmer Arctic will reduce the temperature differences between the Arctic and warmer latitudes, leading to a weaker jet stream that would be more likely to wander off course from time to time. "Of course, we can't say that this particular pattern is due to warming, but it's very consistent with what we expect to see happen," says Jennifer Francis, an atmospheric scientist at Rutgers University in New Brunswick, New Jersey, who published a study on this effect in Geophysical Research Letters in $2012^{1}$.

Judah Cohen, who heads seasonal forecasting for Atmosphere and Environmental Research, a private research firm in Lexington, Massachusetts, suggests that sea-ice melt is a precursor to another powerful driver: Siberian snowpack. Warming increases evaporation, and more water vapor in the air leads to additional snowfall later in the year. His research ${ }^{2}$ suggests that autumn snowpack in Siberia - which was well above normal this past year — is a good predictor of winter severity in places as far away as the United States. Cohen says that the combination of melting sea ice and extra Siberian snow seems to ripple through the Arctic weather system, destabilizing the polar jet stream and leading to colder winters on the northern continents.

\section{Do scientists agree that Arctic warming could be driving these weather patterns?}

These ideas are hotly contested. The exact mechanisms at work are not clear. Some researchers say it is just as likely that warmer air currents from the south could be destabilizing the jet stream. If Arctic warming were to blame, the effect should be the strongest in the northern hemisphere's summer and fall, says Kevin Trenberth, a climate scientist at the National Center for Atmospheric Research in Boulder, Colorado. Moreover, Trenberth says, it is unclear how this seasonal warming effect would persist into the dead of winter.

\section{Is this kind of unstable jet-stream activity on the rise?}

Probably not, according to research ${ }^{3}$ published in September by Elizabeth Barnes, an atmospheric scientist at Colorado State University in Fort Collins. Barnes' analysis of data from 1980 to 2011 found no evidence that this kind of weather system is increasing in frequency. She also did not find any connection between a warming Arctic and a meandering of the jet stream.

Nature | doi:10.1038/nature.2014.14485

\section{References}

1. Francis, J.A. \& Vavrus, S.J. Geophys. Res. Lett. 39, L06801 (2012).

2. Cohen, J., Jones, J., Furtado, J.C., Tziperman, E. Oceanogr. 26, http://dx.doi.org/10.5670oceanog.2013.70 (2013).

3. Barnes, E. A. Geophys. Res. Lett. 40, 4734-4739 (2013). 